\title{
Performance testing of reflective insulation applied in a prototype experimental chamber in Greece: experimental results for summer and winter periods
}

\author{
M. Gr. Vrachopoulos, D. G. Stavlas, L. D. Kravvaritis, \\ M. K. Koukou, N. W. Vlachakis, N. G. Orfanoudakis, \\ S. A. Mavromatis \& A. G. Gonidis \\ Environmental Research Laboratory, Department of Mechanical \\ Engineering, Technological Educational Institution of Halkida, \\ Psachna, GR-34400, Greece
}

\begin{abstract}
With the aim of evaluating a reflective insulation's performance for utilization in the Greek climate, an experimental chamber facility has been designed and constructed at the campus of the Technological Educational Institution of Halkida, located in the agricultural area of Psachna in Evia island at Central Greece. The side-walls are a two series brick construction with a bubble material laminated between layers of aluminum foil placed in the $20 \mathrm{~mm}$ gap of the brick layers. Results indicate that the existence of reflective insulation during the summer period averts the super heating at the interior of the experimental chamber while during winter the heat is retained in the chamber.
\end{abstract}

Keywords: reflective insulation, test room, measurement.

\section{Introduction}

Today, the increment of energy efficiency and the exploitation of renewable energy sources are effective ways of reducing the impacts of global warming and improving air quality while it is also an economically effective choice for consumers. The commercial and residential building sector is responsible for a large portion of the total energy consumption on a national level $[1,2]$. 
This consumption heavily concerns the covering of buildings energy demands.

In EU level the importance of energy conservation in the building sector is depicted from the Directive of the European Parliament and of the Council on the energy performance of buildings [3,4]. The Directive indicates the necessity and possibility of savings through the implementation of standard energy efficiency methods and innovative technologies, including renewable energy. In Greece, the Rule for Rational Use and Energy Savings enacted in 1998, imposes that energy consumption reduction measures should be made compulsory for all buildings by 2007 [5]. The use of energy in Greek buildings, constitutes 30\% of total national energy demand and contributes about $40 \%$ of carbon dioxide emissions [6]. It should be also taken into account that climatic conditions in Greece differ from mild winters to hot summers in the south and rather cold winters to mild summers in the north of the country. These variations in climatic conditions influence in one hand the energy demand and consumption of buildings, and on the other hand the measures concerning potential and costeffectiveness of energy conservation and those related to the exploitation of renewable energy solutions .

The peak load can be reduced by simple techniques and methods. One of them is the proper design of a building envelope and the selection of its components. The proper use of thermal insulation in buildings contributes in reducing the required air-conditioning system size and the annual energy cost. Thermal insulation is a material or a combination of materials, that, when properly applied, retards the rate of heat flow due to its high thermal resistance. For the evaluation of the performance of different insulation materials it is necessary to understand the way that heat is transferred through the composite multilayer wall construction $[7,8]$.

In this work, aiming to the evaluation of reflective insulation's behavior for both summer and winter periods under Greek climate conditions a test room facility has been designed and constructed at the campus of the Technological Educational Institution of Halkida located in the agricultural area of Psachna at Central Greece. The side-walls are a two series brick construction with a bubble material laminated between layers of aluminum foil placed in the $20 \mathrm{~mm}$ gap of the brick layers. Research work will be carried out through various steps. At the current first step, the outer surface of the test room wall construction is not covered with plaster. Temperature measurements have already been conducted so as to obtain a clear understanding of the reflective insulation behavior for this configuration. Experimental results show that the existence of reflective insulation during summer period deters the super heating at the interior of the test room. Due to reflective insulation's characteristics a better attenuation of temperature variations is achieved and a normal behaviour in temperature variation through the wall construction is noticed. During winter period heat remains in the test room, causing the internal temperature stabilization and the respective thermal load decrease. 


\section{Experimental set-up}

\subsection{About reflective insulation}

Reflective insulation consists of one or more low emittance surfaces, such as metallic foil or metallic deposits, unmounted or mounted on substrates [9]. Because reflective insulation is usually manufactured with highly reflective, aluminum foil surfaces, $95-97 \%$ of the radiant heat that strikes the surface is reflected, and only $3-5 \%$ of the heat is emitted through the insulation. The major benefit of this reflective property is that in winter, heat inside a building is reflected off the insulation's surface back into the building so that the heat is retained inside. In the summer, heat radiated through the roof is reflected off the insulation's surface back to the roof and not inside the building thus maintaining lower internal temperatures. Unlike other insulation materials, reflective insulation reflects incident infrared radiation, thus reducing radiant heat transfer. Its performance depends on a number of factors [10] including the radiation angle of incidence on the reflective surface, temperature difference between the spaces on both sides of the reflective material, material emissivity, thickness of the air space facing the reflective material, heat flow direction.

\subsection{Test room development}

A small-scale test room facility has been designed and constructed on the purpose of conducting experiments under various test conditions to evaluate various thermal insulation materials and techniques, heating/cooling/ventilation technologies, etc. The test room is located at the campus of the Technical University of Halkida in the rural area of Psachna in Evia island at Central Greece (Figure 1). The dimensions of the test room are $4 \mathrm{~m} \times 6 \mathrm{~m} \times 4 \mathrm{~m}$ and its roof is covered with roman tiles and a radiant barrier reflective insulation system.

The side walls are a two series brick construction with a bubble material lamination among layers of aluminum foil placed in the $20 \mathrm{~mm}$ gap of the brick layers. The total wall thickness consists of $90 \mathrm{~mm}$ brick, $10 \mathrm{~mm}$ air gap, $1 \mathrm{~mm}$ or $2 \mathrm{~mm}$ reflective insulation, $10 \mathrm{~mm}$ air gap and $90 \mathrm{~mm}$ brick. The walls can be coated internally and externally resulting to a total width ranging from $200 \mathrm{~mm}$ to $240 \mathrm{~mm}$ (including a $20 \mathrm{~mm}$ thickness of the wall sheathing-plaster on each side).

Two doors are located in the north and south-facing walls thus achieving the ventilation of the chamber. A small partition with the height of $1 \mathrm{~m}$ is located adjacent to the north wall. Reflective insulation is a part of the test room wall construction, and more specifically: 1 . Heat insulation material of the vertical wall construction to all directions (North, South, East, West), 2. Temperature and humidity insulation element of the roof.

The roof constructed of roman tiles is based on a wooden support which is protected through the application of reflective insulation and consists of the following layers: joists support of roof, wooden support with thickness 10-15 $\mathrm{mm}$, cleats of reflective insulation and tiles (wooden or other material e.g. plastic) with thickness $2 \times 10 \mathrm{~mm}$, and roman tile. 


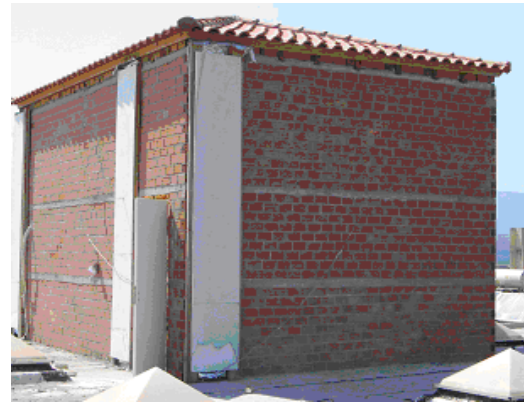

(a)

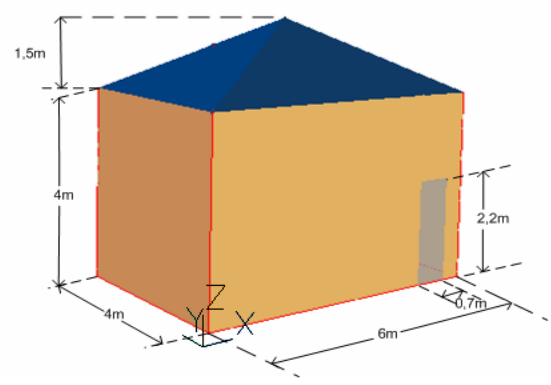

(b)

Figure 1: (a) Experimental chamber; (b) geometrical details.

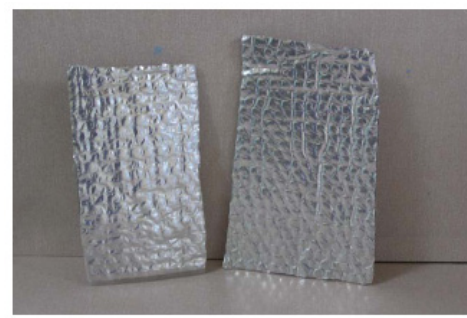

(a)

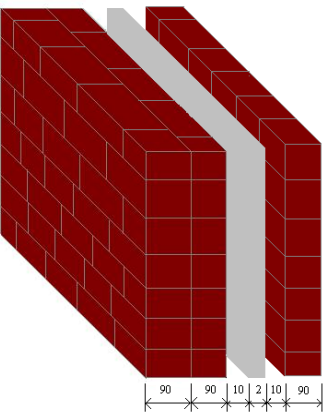

(b)

Figure 2: $\quad$ (a) Reflective insulation; (b) three dimensional view of the wall construction.

\subsection{Experimental plan - data acquisition}

Experimental methodology is compatible with the international standards and certified methods $[11,12]$ for the determination of the wall construction's and the other elements of the building cell, thermal behaviour. Based on the development of the periodic environmental behavior on a $24 \mathrm{~h}$ basis and measurement analysis, the total contribution of reflective insulation to the energy operation of the wall construction (for each orientation), the solar roof and the overall behaviour of the test room can be certified.

Data acquisition has been divided into two sub-sections (Figure 3), one for temperature measurements and one for evaluation of weather conditions. Measurements have been obtained during the period February-November 2007.

The experimental equipment used for the evaluation of reflective insulation consists of temperature sensors connected to a data logging system $[13,14]$. The logging system has a 10 minute recording frequency. Temperatures were measured at different levels inside and outside the test room as well as inside the 
wall construction as shown in Figure 4. Twenty four thermocouples (six for each orientation) were connected to four modules which transmitted the signals to a RS-232 converter connected with a PC. The K type thermocouples were placed at the middle of each orientation both at the outer and internal wall.

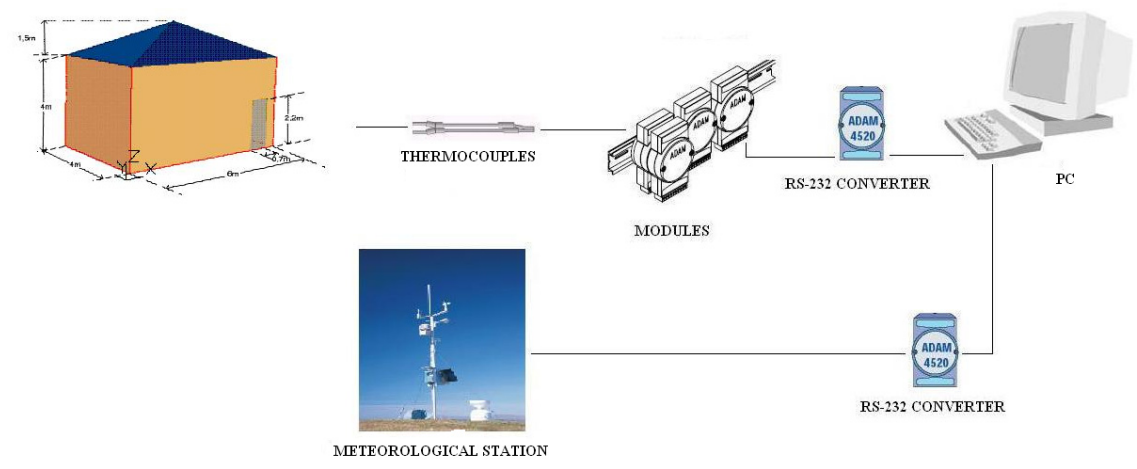

Figure 3: Data acquisition.

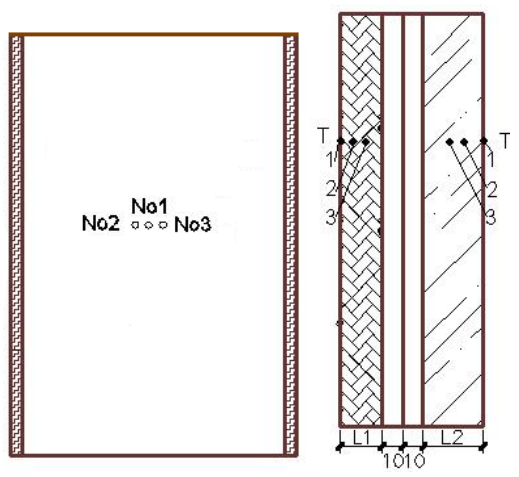

Figure 4: Temperature sensors inside the wall.

Finally, a meteorological station equipped with components and sensors that measure wind speed, wind direction, rain gauge, air pressure, temperature, relative humidity, total solar radiation and diffused solar radiation, was installed focusing on the determination of the external environment thermal behaviour. All the sensors were connected to a PC and through the use of special software measurements could be read.

\section{Typical results and discussion}

In this section, typical results from measurements inside and outside the test room, obtained during winter and summer periods, are presented and discussed. During the experimental period, the meteorological conditions were characterized by clear sky, quite high temperature and low wind speed. 


\subsection{Winter period}

In Figure 5 temperature curves for the period 21-28 February 2007 and for south orientation are presented while Figure 6 shows temperature curves for a typical winter day. It can be noticed that the temperature range of the internal wall is quite smaller than of the outer one. During a typical winter day while outer wall temperature ranges from 6 to $16{ }^{\circ} \mathrm{C}$ the inner wall temperature remains quite constant from 10 to $12{ }^{\circ} \mathrm{C}$ (Figure 6). This is due to reflective insulation, which

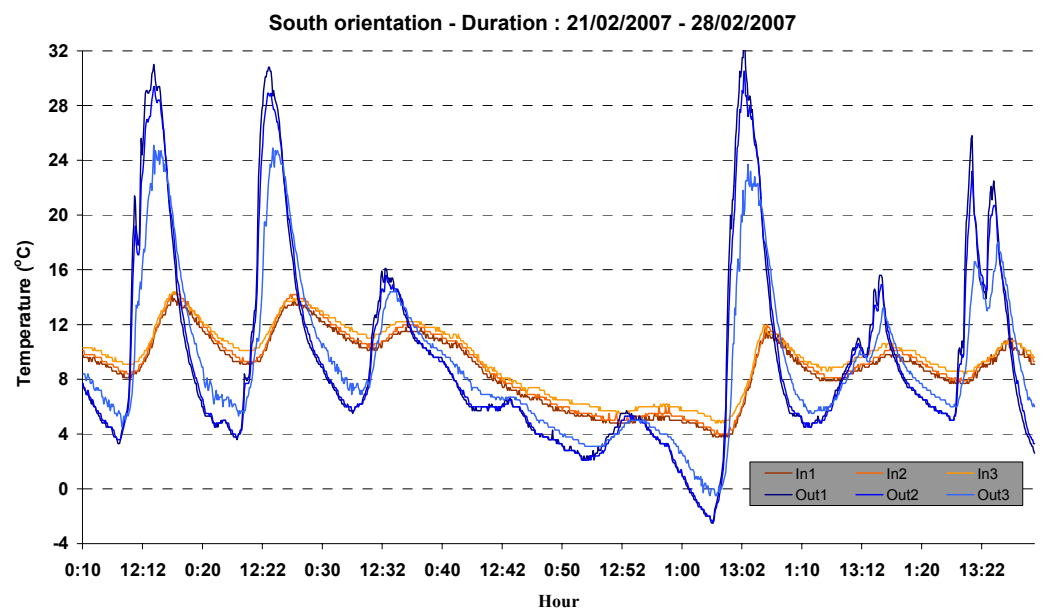

Figure 5: Temperature of inner and outer wall for south orientation - Period: $21-28 / 2 / 07$.

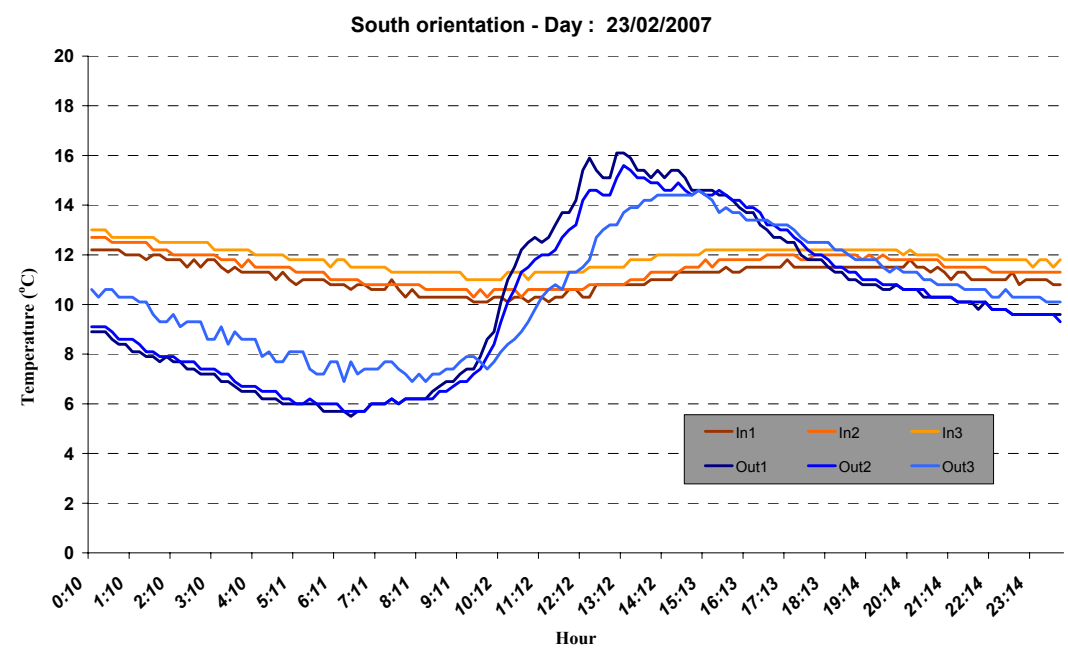

Figure 6: Temperature of inner and outer wall for south orientation - Period: 23/2/07. 
during winter period permits heat reflection to the test room interior and thus heat remains in it causing the internal temperature stabilization and the respective decrease of thermal loads. The same behavior is noticed from the results of all test room orientations.

\subsection{Summer period}

During the summer period as is shown in Figures 7 and 8 despite external wall's high temperature variations the temperature variation at the internal walls and inside the test room is quite mild. Temperatures at the surface of the external wall of the test room ranges from $16^{\circ} \mathrm{C}$ early in the morning to about $32^{\circ} \mathrm{C}$ at 15:00-16:00 in the afternoon as it was expected. However, temperature at the surface of the internal wall of the test room is about $23-25^{\circ} \mathrm{C}$ during the whole day causing decrease in the required loads for the test room air conditioning. This is mainly due to the existence of reflective insulation which during the summer period deters the super heating at the interior of the test room. When solar radiation falls on to a non-transparent surface, like the test room walls, the outer surface absorbs a part of the radiation which is transformed to heat. A part of the heat is re-emitted to the outside while the rest is driven through the wall to the test room interior with a rate depending on the thermal characteristics of the wall construction materials. Because of the reflective insulation characteristics, a better attenuation of temperature variations is achieved and a normal behavior in temperature variation through the wall construction is noticed. This is due to the time duration between the peak of the outside temperature (about 19:00) and the peak of the inside surface temperature (about 21:00). Actually, a time delay of two hours means that the test room wall construction materials will start to reject heat to the test room interior during the night (when there is a demand for heating during the winter or when room cooling is feasible through ventilation

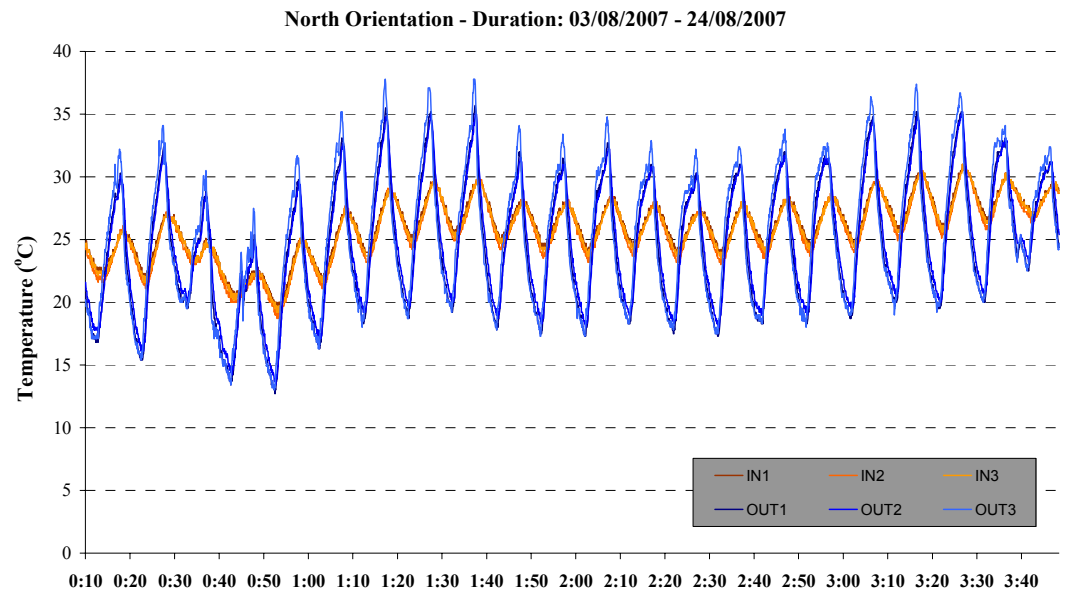

Figure 7: Temperature of inner and outer wall for north orientation - Period: $3-24 / 8 / 07$. 


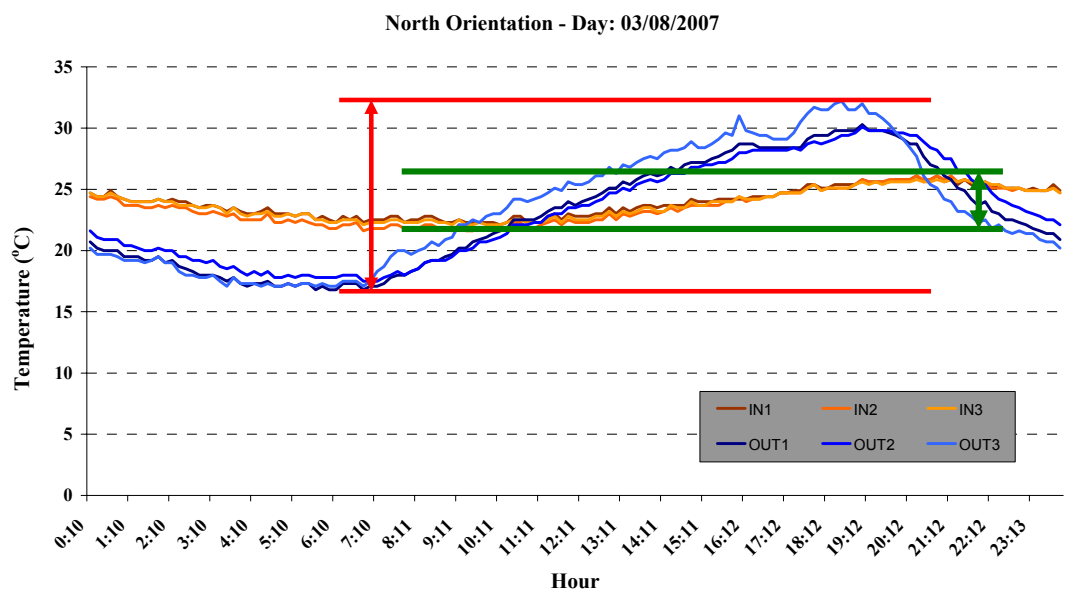

Figure 8: $\quad$ Temperature of inner and outer wall for north orientation - Period: $3 / 8 / 07$.

during summer). In light constructions, there is a small time delay and thus outside temperature variations become tangible at the building interior quite quickly. During the night, air temperature at the test room interior is higher in comparison with the outside temperature and there is a heat flow to the outside causing the decrease of the wall temperature together with the temperature at the room interiors. Consequently, at the next day, the room becomes quite cool so as to be able to absorb again the undesired heat. The same behavior is noticed from the results of all test room orientations.

\section{Conclusions}

In the present work, the possibility to exploit reflective insulation in Greek climate has been investigated focusing on the improvement of building insulation behavior. For that purpose, an experimental chamber facility has been designed and constructed at the campus of the Technological Educational Institution of Halkida, located in the agricultural area of Psachna in Evia island at Central Greece. Results show that during winter period reflective insulation permits heat reflection to the test room interior and thus heat remains in it causing the internal temperature stabilization and the respective decrease of thermal load. During the summer period, reflective insulation deters the super heating at the interior of the test room, a better attenuation of temperature variations is achieved and a normal behavior in temperature variation through the wall construction is noticed.

\section{Acknowledgement}

This research work was co-funded by the European Social Fund (75\%) and National resources (25\%) through the Operational Program for Educational and Vocational Training II (EPEAEK II) “Archimedes II". 


\section{References}

[1] IPCC 1996. Technologies, Policies and Measures for Mitigating Climate Change - IPCC Technical Paper 1; Geneva: Intergovernmental Panel on Climate Change; 84pp.

[2] Zografakis, N., Technologies for rational use and savings of energy in buildings. Energy (in Greek), 62, pp. 112-114, 2000.

[3] Directive 2002/91/EC of the European Parliament and of the Council of 16 December 2002 on the energy performance of buildings, 4/1/2003, Official Journal L1 65.

[4] Chwieduk, D., Towards sustainable-energy buildings. Applied Energy, 76, pp. 211-217, 2003.

[5] Joint-Ministerial Decision 21475/4707 for the reduction of CO2 emissions by means of energy efficiency improvement in buildings. Government Newspaper, No. 880, 19th August 1998.

[6] Regulating Authority for Energy (RAE), The Energy System in Greece [in Greek] (http://www.rae.gr/energysys/main.htm).

[7] Incropera, F.P. \& DeWitt, D.P., Fundamentals of Heat Transfer, $4^{\text {th }}$ Ed., John Wiley \& Sons, New York, 1996.

[8] Bird, R.B., Stewart, W.E. \& Lightfoot, E.N., Transport Phenomena, John Wiley \& Sons, New York, 1960.

[9] ASTM C1224-03 Standard Specification for Reflective Insulation for Building Applications, ASTM International, 2005.

[10] American Society of Heating, Refrigerating, and Air Conditioning Engineers (ASHRAE). Handbook of Fundamentals, Atlanta, GA, USA, 2001 [Chapter 23].

[11] ASTM C177-04 Standard Test Method for Steady-State Heat Flux Measurements and Thermal Transmission Properties by Means of the Guarded-Hot-Plate Apparatus, ASTM International.

[12] ISO 7726, Ergonomics of the thermal environment - Instruments for measuring physical quantities, International Organization for Standardization, Geneva, Switzerland, 1998.

[13] Supco DLTH Temperature/Humidity Data Loggers, Instruction manual, USA, 2002.

[14] Supco LOGiTpc Interface Software, User's Guide, USA, 2002. 